\title{
Warm welcome to the new MBEC Editor-in-Chief and his team
}

\author{
Ratko Magjarević
}

Published online: 11 February 2013

(C) International Federation for Medical and Biological Engineering 2013

In 2012, the year of celebration of the 50th Anniversary of Medical \& Biological Engineering \& Computing (MBEC), the International Federation of Medical and Biological Engineering (IFMBE) was searching for a new Editor-inChief for the journal. The previous Editor, Jos A.E. Spaan, decided to retire after 7 years of dedicated service ensuring timely release of monthly issues of the MBEC journal. The task of selecting the new MBEC Editor-in-Chief (EiC) was undoubtedly arduous and the necessary procedures took substantial amount of time mainly because the Administrative Council of IFMBE wanted to ensure the selection of the right person to lead the efforts in making MBEC a top quality journal. I am pleased to welcome Nitish Thakor who has accepted the position of MBEC Editor-in-Chief. Let me give you some of the major considerations which led to his appointment as the EiC for MBEC.

Professor Nitish Thakor is a respected researcher with a large number (over 280) of peer reviewed publications in best journals in the field of Biomedical Engineering and attaining an h-index as high as 36 [1]. In his bibliography, there is a quote of a paper on model-based analysis of deep brain stimulation from 2009 which was cited over 210 times [2]. Nitish is very familiar with the Federation's journal just as the readers of MBEC are familiar with him, since his first paper in MBEC was published in 1982 [3], and in the years to follow he published another 12 papers as author or coauthor. Some of his papers were very well received and are highly cited $[4,5]$. In addition to his proven track record of publications, Nitish has a rich experience as an Editor of journals in the field of biomedical engineering. From 2005

R. Magjarević ( $\square)$

Faculty of Electrical Engineering and Computing, University of Zagreb, Unska 3, 10000 Zagreb, Croatia

e-mail: ratko.magjarevic@fer.hr to 2011, he was the Editor-in-Chief of the IEEE Transactions on Neural and Rehabilitation Engineering. He served as an Associate Editor in IEEE Transactions on Biomedical Engineering (1989-2002), IEEE Transactions on Information Technology (1996-2002), Journal of Ambulatory Monitoring (1988-1994), Journal of Biological Systems (1992-1996), Nanobiotechnology (2005-2008), and he also kept the position of Associate Editor in Annals of Biomedical Engineering and Biomedical Microdevices and Nanotechnology.

A significant reason for decision of IFMBE's Administrative Council to appoint Nitish Thakor as EiC of MBEC is his established leadership in biomedical engineering and computing research, in particular in neurotechnology where he has superior experience in areas of neural diagnostic instrumentation, neural signal processing, neural microsystem, neural control of prosthesis, brain machine interface and optical imaging of the nervous system. MBEC journal covers a wide range of topics in the rapidly growing field of biomedical engineering and the journal and its readers will greatly benefit from the focused interest and distinct proficiency of its new EiC in the area of neurotechnology. All through the search, interview and decision phases in the selection of the new MBEC EiC, abundant time and effort were spent by the Members of the Search Committee. Nitish was providing interesting and exciting ideas on how to open new frontiers for inputs to the journal in support of the Federation's mission. The numerous discussions I had with Nitish convinced me that he has a solid plan on expanding MBEC to include new, emerging and currently-not-covered areas of biomedical engineering. Along with the new Editor-in-Chief, several new Associate Editors will be recruited, to take the place of some previous Associate editors. The new team under the leadership of Nitish will enrich the efforts with the 
combined experience and expertise to attain and sustain the excellence in the broad spectrum of related scientific and technological areas keeping pace with the changing and challenging times.

What kind of journal is the new Editor-in-Chief taking into his hands this January? From the time when the IFMBE contracted Springer Verlag as the official publisher of all IFMBE publications in 2006 [6], MBEC had shown immediate growth in volume by the increased number of pages and by monthly issues of the journal instead of bi-monthly issues. The visibility has increased since Springer improved dissemination by introducing MBEC into 200 consortia and through that MBEC reached more than 4,000 institutions; furthermore since MBEC added a completely web-based version, it has also reached numerous personal computers of researchers, engineers, scientists, professionals and students [6]. During the last 7 years, the impact of MBEC, measured by its impact factor, reached 1.878 which is approximately twice the attained value before the change of the publisher. MBEC is a journal positioned in Q2 in all four WoS categories: computer science-interdisciplinary applications, biomedical engineering, mathematical and computational biology and, finally, medical informatics [1]. The detailed analysis of the development of the journal in the last 7 years and the reflections of the period by the outgoing MBEC Editor-inChief and his Deputy were published in the 2012 December issue of MBEC [7]. Last, but not the least among features of MBEC, it is indeed a special pleasure for IFMBE and the publisher that the authors who published in MBEC had responded to the opinion pool sought by the publisher quoted "journal quality" as the main reason for publishing in MBEC.

The new Editor-in-Chief is certainly actively and enthusiastically building his team for managing the paper review and selection process. The EiC will have to deal with numerous challenges of publishing in current times: constant time pressure to deal with ever increasing number of manuscript submissions, expected quick reviews, diligent decision making and prudent balancing assignments of particular papers published in MBEC on open or protected access.

On behalf of the IFMBE, I would like to express my sincere gratitude for all their efforts for MBEC to Jos A.E. Spaan,
MBEC Editor-in-Chief 2006-2012, Ruben Coronel, the Deputy Editor, Associate Editors Dario Farina, Andrew D. McCullock, Nico A.M. Schellart, Maria Siebes and Andreas Wahle, and the members of the Editorial Board who served in previous years: Jordi Aguilo, Gerhard M. Artmann, Dan L. Bader, Chris D. Bertram, Sergio Cerutti, Andrea Giovanni Cutti, Olaf Dössel, Ivar Giaever, Masami Goto, Warren M. Grill, Franc Jager, Sun I. Kim, Chwee Teck Lim, Rod Lakes, Peter W. Macfarlane, Damijan Miklavčič, Ronney B. Panerai, Nic Smith, Leif Sörnmo, Tatsuo Togawa and Karin Wårdell. Many of these outstanding researchers and academicians will continue contributing to MBEC in the future.

While the Administrative Council of IFMBE is proud of the historic progress of the Federation's Journal, we wish to emphasise that all of us will work together giving our full support to the sincere and tireless efforts made by the new Editor-in-Chief and his team with the goal to take MBEC to greater heights so that the IFMBE members as well as all other readers can enjoy the new achievements in biomedical engineering research described in articles published in our journal. I wish the new Editor-in-Chief and his team to have great success with MBEC which will contribute towards the accomplishment of IFMBE's mission.

\section{References}

1. www.webofknowledge.com. Accessed 28 Jan 2013

2. McIntyre CC, Grill WM, Sherman DL, Thakor NV (2004) Cellular effects of deep brain stimulation: model-based analysis of activation and inhibition. J Neurophysiol 91:1457-1469

3. Thakor NV, Webster JG (1982) Design and evaluation of QRS and noise detectors for ambulatory e.c.g. monitors. Med Biol Eng Comput 20:709-714

4. Thakor NV, Webster JG, Tompkins WJ (1983) Optimal QRS detector. Med Biol Eng Comput 21:343-350

5. Laguna P, Thakor NV, Caminal P et al (1990) New algorithm for QT interval analysis in 24-hour holter ECG performance and applications. Med Biol Eng Comput 28:67-73

6. Nagel JH (2006) A new chapter for MBEC. Med Biol Eng Comput 44:3-4

7. Spaan JA, Coronel R (2012) Fifty years of publishing in biomedical engineering: reflections after 7-year editorship. Med Biol Eng Comput 50:1183-1186 